Article

\title{
Physicochemical Characterization and Functional Analysis of the Polysaccharide from the Edible Microalga Nostoc sphaeroides
}

\author{
Haifeng Li ${ }^{1,+}$, Linnan Su ${ }^{1,+}$, Sheng Chen ${ }^{2}$, Libin Zhao ${ }^{2}$, Hongyu Wang ${ }^{1}$, Fei Ding ${ }^{1}$, \\ Hong Chen ${ }^{1}$, Ruona Shi ${ }^{1}$, Yulan Wang ${ }^{2}$ and Zebo Huang ${ }^{1,3, * \text { (iD }}$ \\ 1 Center for Bioresources \& Drug Discovery and School of Biosciences \& Biopharmaceutics, \\ Guangdong Pharmaceutical University, Guangzhou 510006, China; lihf@gdpu.edu.cn (H.L.); \\ sulinnan1234@foxmail.com (L.S.); 15626200071@163.com (H.W.); 15692435199@163.com (F.D.); \\ hongchen1117@163.com (H.C.); 15521217084@163.com (R.S.) \\ 2 Research \& Development Centre, Hunan Yandi Bioengineering Co., Ltd., Zhuzhou 412000, China; \\ chensheng@ydhn.com (S.C.); zhaolibin@ydhn.com (L.Z.); wangyulan@ydhn.com (Y.W.) \\ 3 School of Food Science and Engineering, South China University of Technology, Guangzhou 510641, China \\ * Correspondence: huangzebo@scut.edu.cn; Tel.: +86-20-3935-3631 \\ + These authors contributed equally to this work.
}

Received: 29 January 2018; Accepted: 23 February 2018; Published: 24 February 2018

\begin{abstract}
Nostoc colonies have been used as food and medicine for centuries, and their main supporting matrix is polysaccharides, which help Nostoc cells resist various environmental stresses including oxidative stress. Here we isolated a polysaccharide, nostoglycan, from cultured Nostoc sphaeroides colonies and determined its physicochemical properties, which revealed a characteristic infrared absorption spectrum typical of polysaccharides and an amorphous morphology with rough surfaces. We also show that nostoglycan has strong moisture absorption and retention capacities and a high relative viscosity. Using Caenorhabditis elegans models, we then demonstrate that nostoglycan is capable of improving overall survival rate of the animals under increased oxidative stress caused by paraquat. Nostoglycan also reduces reactive oxygen species level, inhibits protein carbonyl formation and lipid peroxidation, and increases activities of superoxide dismutase and catalase in paraquat-exposed nematodes. As oxidative stress may drive tumor progression, we further demonstrate that nostoglycan can suppress the proliferation of several types of tumor cells and induce apoptosis of human lung adenocarcinoma A549 cells via caspase-3 activation. Together, our results yield important information on the physicochemical characteristics and demonstrate the antioxidant and anti-proliferative functions of nostoglycan, and thus provide an insight into its potential in food and health industries.
\end{abstract}

Keywords: Nostoc sphaeroides; polysaccharide; Caenorhabditis elegans; oxidative stress; apoptosis

\section{Introduction}

Nostoc is a genus of nitrogen-fixing cyanobacteria that can form gelatinous colonies composed of filaments of moniliform cells in a range of environments. Nostoc sphaeroides, for instance, grows naturally in the form of spherical macrocolonies of dark green appearance during the winter in some mountain paddy fields in China [1]. Traditionally, N. sphaeroides and other Nostoc colonies have been collected from natural habitats and used as food delicacy and herbal medicine in Asia, Europe, and America [1-4]. For example, N. sphaeroides is known as Ge-Xian-Mi in Chinese, named after Ge Hong, an influential scholar in Taoism, alchemy and medicine in Jin Dynasty (265-420). According to the autobiography of the last Chinese emperor Henry Pu Yi, Ge-Xian-Mi was fried 
with diced duck meat and served at royal meals of Qing Dynasty (1644-1912). In Supplement to Compendium of Materia Medica (Bencao Gangmu Shiyi) written by Zhao Xuemin (1719-1805) in Qing Dynasty, N. sphaeroides was recorded to treat a variety of medical conditions such as inflammation, burns, hypertension, nyctalopia and chronic fatigue. Interestingly, recent studies have revealed the nutritional and pharmacological benefits of N. sphaeroides (or Nostoc commune var. sphaeroides), including anti-inflammatory, anti-hyperlipidemic, and atheroprotective effects [5-7].

Endogenous reactive oxygen species (ROS) are byproducts of normal metabolism of oxygen, primarily generated from the respiratory chain of mitochondria [8]. These small reactive molecules are normally present at low levels inside cells and play important roles in a range of biological processes such as regulation of cell signaling and homeostasis [9]. Due to their highly reactive nature, however, excessive ROS can make cellular macromolecules vulnerable to oxidation [8]. Under persistent intrinsic as well as extrinsic stress, ROS levels may increase to an extent that exceeds physiological levels and overwhelms the antioxidant defense machinery of cells. When ROS production outpaces ROS scavenging by the endogenous antioxidant system, an excessive accumulation of ROS occurs and induces a state of oxidative stress, which may cause damage to cellular components and result in a disruption of cellular function [8]. It is also established that oxidative stress is implicated in a number of diseases and conditions, including cancer, inflammation, and neurodegeneration [10,11]. A high ROS level, for instance, can trigger carcinogenesis and promote tumor progression via cell proliferation and cell death pathways [10]. Therefore, amelioration of oxidative stress and associated damages represents a valuable approach for health maintenance and disease prevention. For example, adequate consumption of food-derived antioxidants such as antioxidant polysaccharides has been reported to reduce oxidative damages and to be beneficial to both human and animal health [12-14].

Nostoc colonies are commonly grown on soil surface and thus have developed a number of strategies to resist various environmental stresses, including extreme desiccation and intense solar ultraviolet radiation, both of which can stimulate ROS generation and induce oxidative damages $[1,15,16]$. The major adaptive strategies of Nostoc against desiccation, ultraviolet radiation, and other environmental conditions are closely associated with their abundant extracellular polysaccharides $[1,4,15]$. Interestingly, these polysaccharides are also shown to have beneficial effects such as complement-fixing and antioxidant activities [2,4,17]. For example, a polysaccharide from $N$. sphaeroides is capable of scavenging superoxide, hydroxyl, and DPPH radicals, demonstrating its in vitro antioxidant capacity [17]. However, in vivo antioxidant studies as well as physicochemical characterization of $N$. sphaeroides polysaccharides are lacking. Here we first determined the physicochemical properties of a polysaccharide isolated from N. sphaeroides (nostoglycan). Then we tested the in vivo antioxidant capacities of nostoglycan using Caenorhabditis elegans, a simple but powerful animal model widely used in biomedical studies, under paraquat-induced oxidative stress. We further examined the anti-proliferative activities of nostoglycan using several human tumor cell lines as oxidative stress is known to be involved in cancer development. Finally, we investigated the effect of nostoglycan on cell apoptosis and caspase-3 activation.

\section{Results and Discussion}

\subsection{Physicochemical Characterization of Nostoglycan}

The yield of water-soluble polysaccharide from N. sphaeroides (nostoglycan) was $\sim 30 \%$ after removal of proteins by papain digestion and purification by ethanol precipitation, and its total carbohydrate content was $\sim 80 \%$. The molecular weight distribution of nostoglycan was assessed by high-performance gel permeation chromatography [18], which showed a distinct peak (data not shown) with a weight-average molecular weight $(\mathrm{Mw})$ of $1.99 \times 10^{3} \mathrm{kDa}$ and a number-average molecular weight $(\mathrm{Mn})$ of $0.99 \times 10^{3} \mathrm{kDa}$. The monosaccharide molar ratio of nostoglycan was $34.5 \%$ mannose, $21.8 \%$ fructose, $14.6 \%$ galactose, $17.7 \%$ glucose, $6.1 \%$ xylose, $2.2 \%$ rhamnose, and $3.1 \%$ galacturonic acid. As revealed previously using methylation and gas chromatography-mass 
spectrometry analysis, xylose, glucose, and galactose were $1 \rightarrow 4$ linked; mannose, galactose, and xylose were terminal groups; and branch points occurred in glucose as $1 \rightarrow 3,4$ and $1 \rightarrow 3,6$ linkages and in xylose as a $1 \rightarrow 3,4$ linkage [1].

Fourier transform infrared (FTIR) spectroscopy is a powerful tool to identify major organofunctional groups and chemical bonds in polymers, and thus was used to characterize the spectroscopic properties of nostoglycan. As shown in Figure 1A, a broad and intense peak at $3424 \mathrm{~cm}^{-1}$ was observed, demonstrating the presence of the stretching vibration of hydroxyl groups. The bands at $2924 \mathrm{~cm}^{-1}$ and $1425 \mathrm{~cm}^{-1}$, which can be attributed to $\mathrm{C}-\mathrm{H}$ stretching vibration and deforming vibration, respectively, were also present in the spectrum. The peaks at $1618 \mathrm{~cm}^{-1}$ and $1047 \mathrm{~cm}^{-1}$ were assigned to the stretching vibrations of $\mathrm{C}=\mathrm{O}$ and $\mathrm{C}-\mathrm{O}$, respectively, indicating the existence of carboxyl groups. Moreover, the band at $806 \mathrm{~cm}^{-1}$ was consistent with the presence of $\alpha$-type glycosidic linkages between glycosyl residues. Collectively, the infrared spectrum of nostoglycan revealed the characteristic absorption bands typical of polysaccharides.
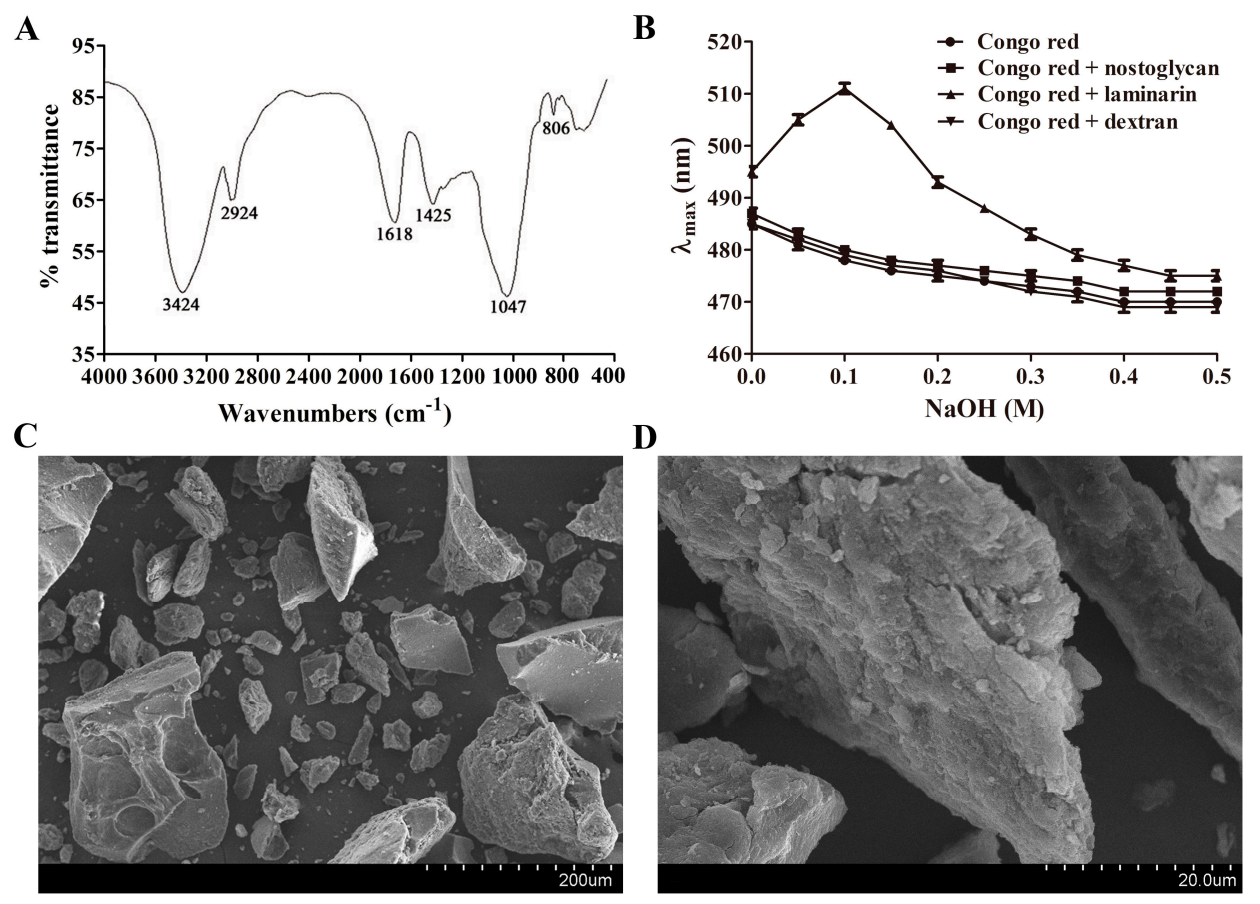

Figure 1. Spectroscopic and physicochemical characterization of nostoglycan. (A) FTIR spectrum of nostoglycan in the frequency range of $4000-400 \mathrm{~cm}^{-1}$; (B) Triple helical conformation analysis of polysaccharides in aqueous solution. The maximum absorption wavelength of Congo red in the absence or presence of an indicated polysaccharide was recorded by a spectrophotometer under increasing alkaline conditions (0-0.5 M NaOH); (C,D) Surface morphology of nostoglycan by scanning electron microscopy at $200 \times$ and $2000 \times$ magnification, respectively.

Polysaccharides in aqueous solution can have different chain conformations such as random coil, various helices, aggregate, and sphere [19]. Interestingly, the bioactivities of some polysaccharides may, as reported, be related to their triple helical conformation [19-21]. For example, lentinan, an antitumor $\beta-1,3-\mathrm{D}$-glucan isolated from the mushroom Lentinus edodes, is shown to have a triple helical conformation [19]. Therefore, we tested whether nostoglycan can form a triple helical conformation in aqueous solution using Congo red binding assay, a valuable approach that has been used to detect conformational transition of triple helix to coil in various polysaccharides, including heteropolysaccharides [21]. The anionic dye Congo red can combine polymers with triple helical structure, resulting in a red shift of the maximum absorption [20]. However, alkali such as $\mathrm{NaOH}$ can disrupt intermolecular as well as intramolecular hydrogen bonds in triple helix, inducing a 
conformational transition to random coil [20]. As shown in Figure 1B, the maximum absorption wavelength $\left(\lambda_{\max }\right)$ of Congo red and laminarin mixture first increased from $495 \mathrm{~nm}$ to $511 \mathrm{~nm}$ as $\mathrm{NaOH}$ concentration increased to $0.1 \mathrm{M}$ and then gradually decreased when $\mathrm{NaOH}$ concentration increased further to $0.5 \mathrm{M}$, indicating the formation of a Congo red-laminarin complex. However, the bathochromic shift was not observed when Congo red was incubated with nostoglycan or dextran, suggesting the absence of a complex with Congo red. These results indicate that nostoglycan does not form a triple helical conformation in aqueous solution.

The surface morphology of substances is closely associated with their physicochemical properties and may affect their biological functions [22]. Scanning electron microscopy (SEM) is known to be an efficient qualitative tool for characterization of microstructural properties such as roughness, porosity, crystallinity, and orientation, and was thus used to investigate the surface morphology of nostoglycan. As shown in Figure 1C, nostoglycan was present as irregular and angular particles with rough surfaces under SEM at $200 \times$ magnification, indicating an amorphous nature of the polysaccharide. A higher magnification at $2000 \times$ revealed the multilayer and flaky morphologies of nostoglycan (Figure 1D). Interestingly, the polysaccharide produced by Nostoc flagelliforme, another edible terrestrial Nostoc species grown in arid and semi-arid areas, is also shown to be porous aggregates with a scaly surface under SEM [23]. However, the surface morphology of polysaccharides may be affected by a number of factors, including preparation methods. For example, spray-dried grewia polysaccharide gum has a more spherical shape and smoother surface as compared to air-dried and freeze-dried grewia polysaccharides [24]. Therefore, further investigation is needed to provide more details on the morphological features of nostoglycan and other Nostoc polysaccharides.

The industrial applications of polysaccharides are often associated with their physical characteristics, such as moisture property and viscosity. Interestingly, the extracellular polysaccharide matrix is also considered to play a critical role in the morphology maintenance of Nostoc colonies per se, particularly during desiccation and rewetting processes [1,25]. We have previously analyzed the moisture buffering capacities of polysaccharide from $N$. commune colonies and the viscosities of polysaccharides from field colonies and suspension cultures of three edible Nostoc species [1,4]. Here we investigated the moisture absorption and retention capabilities of nostoglycan using weight gain-and-loss assay. When the polysaccharides were placed at $43 \%$ relative humidity (RH), the moisture absorption rate $(\mathrm{Ra})$ of nostoglycan was increased at a faster pace than chitosan in the first $12 \mathrm{~h}$ and the Ra of nostoglycan and chitosan was 19.7\% and 16.3\%, respectively, after $24 \mathrm{~h}$ (Figure 2A). When the samples were exposed to $81 \% \mathrm{RH}$, the $\mathrm{Ra}$ of both nostoglycan and chitosan was higher than that at $43 \% \mathrm{RH}$ and reached $28.7 \%$ and $21.4 \%$, respectively, after $24 \mathrm{~h}$ (Figure $2 \mathrm{~B}$ ). To assess the moisture-retention capacity, the polysaccharides were first placed in a water-humidified chamber for $24 \mathrm{~h}$ and then dehydrated at 43\% RH. As shown in Figure $2 \mathrm{C}$, the moisture retention rate ( $\mathrm{Rr}$ ) of both nostoglycan and chitosan was gradually decreased upon dehydration at $43 \% \mathrm{RH}$, which was $58.2 \%$ and $55.6 \%$, respectively, after $12 \mathrm{~h}$. When the samples were further dehydrated in a silica gel chamber, the water loss of nostoglycan and chitosan in the complete dry condition was, as expected, much faster than at $43 \% \mathrm{RH}$ and the $\mathrm{Rr}$ was decreased to $32.5 \%$ and $29.9 \%$, respectively (Figure 2D). Together, these results demonstrate the strong moisture absorption and retention capacities of nostoglycan, which is comparable with chitosan and in agreement with the polysaccharide from N. commune [4]. The rapid water uptake and slow water loss of Nostoc polysaccharides may help Nostoc colonies to maintain their morphology and survive at varying humidity conditions. For example, when the desiccated colonies of $N$. commune were rehydrated, the brittle polysaccharide matrix can rapidly swell into a loose and porous network, which allows fast water absorption [26,27]. On the other hand, this stereoscopic network structure can also efficiently prevent loss of water from the colonies during desiccation [27]. 
A

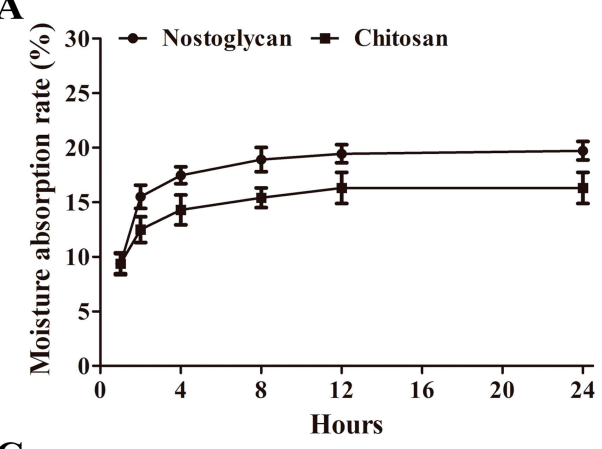

C

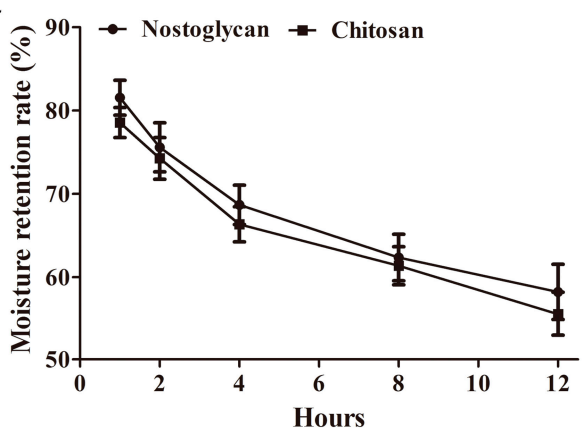

B

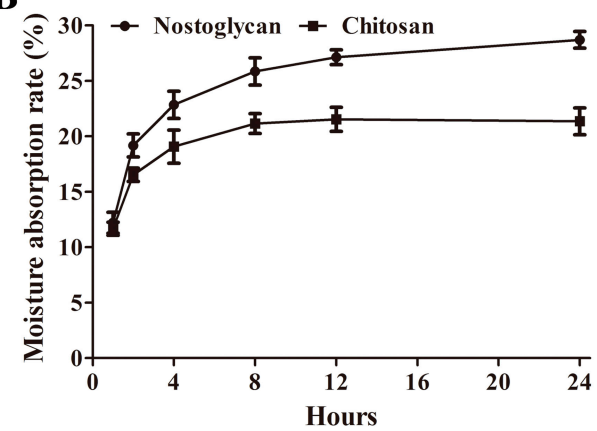

D

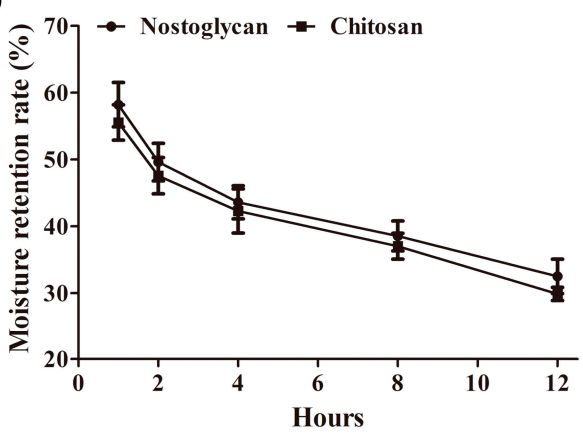

Figure 2. Moisture absorption and retention rates of nostoglycan. For moisture absorption analysis, the dried polysaccharides were placed at $43 \%$ (A) or $81 \%$ (B) RH for the indicated times. For moisture retention determination, the humidified polysaccharides were first placed at $43 \% \mathrm{RH}$ for $12 \mathrm{~h}(\mathrm{C})$ and then in a silica gel chamber for the indicated times (D). Both moisture gain and loss were determined gravimetrically. Data are representative of three independent experiments and shown as mean \pm SD.

Rheological properties of polysaccharides may also affect their water retention capacity and application potentials. For example, hyaluronic acid, a polysaccharide naturally present in the extracellular matrix of vertebrate tissues, has been widely used as moisturizer and humectant in a range of biomedical and cosmetic products due, at least partly, to its high viscosity. Therefore, we measured the viscosity of nostoglycan, which showed a high relative viscosity (1.78) as compared to pectin and agar (1.56 and 1.39, respectively). This is in agreement with our previous findings that the polysaccharides isolated from Nostoc colonies collected from the field also have high kinematic viscosities [1]. A recent study has revealed that $N$. sphaeroides polysaccharides can form a gel system in aqueous solution, which may be associated with the branch structures of the polysaccharides [28]. Interestingly, the polysaccharides from $N$. commune are shown to contain the nosturonic acid $\{3-O-[(R)-1$-carboxyethyl]-D-glucuronic acid\} pendant group, which is proposed to play a role in modulating the specific rheological property of Nostoc polysaccharides and in the water flux of Nostoc colonies $[25,26]$. To date, however, the presence of nosturonic acid in the polysaccharides of $N$. sphaeroides remains unknown. Together, these results suggest that the viscous Nostoc polysaccharides not only have a moisture-buffering effect in the maintenance of their colony morphology but also have industrial potentials as thickening and emulsifying agents.

\subsection{Increase of Survival Rate and Reduction of ROS Levels by Nostoglycan in C. elegans under Oxidative Stress}

Extensive studies suggest that persistent oxidative stress can accelerate ageing process and reduce life expectancy in animal models, and dietary supplementation of antioxidants is shown to be a promising strategy to reduce oxidative damages and increase oxidative survival [29-32]. The polysaccharides isolated from $N$. sphaeroides have been previously shown to scavenge free radicals in vitro [17], suggesting their potential to attenuate free radical-mediated oxidative stress. An in vitro antioxidant effect, however, does not necessarily imply an in vivo antioxidant function. Thus, we 
investigated the antioxidant activity of nostoglycan in C. elegans, a convenient animal model for stress survival studies, under increased oxidative stress elicited by paraquat, which is a potent ROS generator known to induce oxidative damages in animals and humans [33]. Wild-type nematodes were first treated with $0-0.5 \mathrm{mg} / \mathrm{mL}$ of nostoglycan for $48 \mathrm{~h}$ and then exposed to $70 \mathrm{mM}$ paraquat, and the survival rates were determined. As shown in Figure $3 \mathrm{~A}$, the survival rates of nematodes pretreated with nostoglycan at 0.25 and $0.5 \mathrm{mg} / \mathrm{mL}$ were increased as compared to that of the nematodes exposed to paraquat alone $(p<0.05)$, at a similar level with the well-known antioxidant epigallocatechin-3-gallate (EGCG). These results indicate that nostoglycan is capable of attenuating oxidative damages in animal models.

A

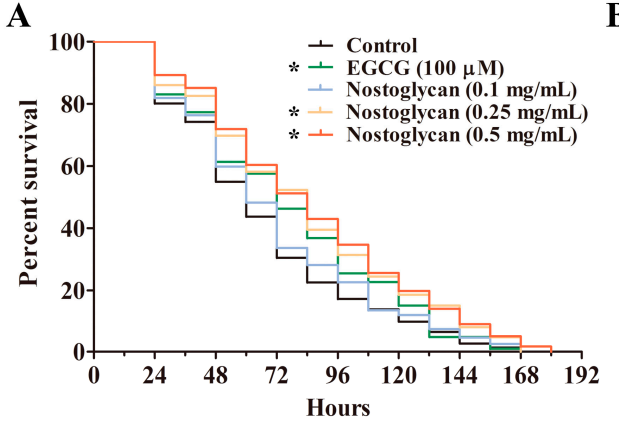

B

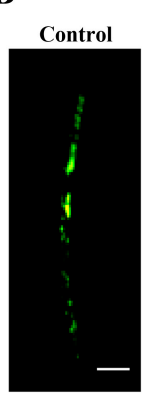

C

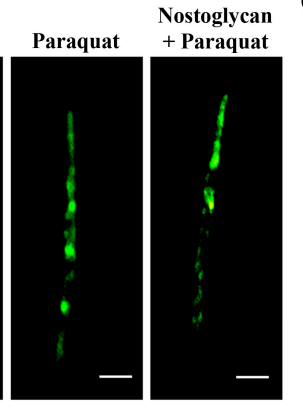

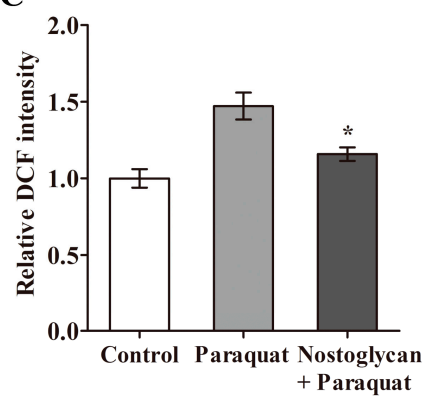

Figure 3. Effect of nostoglycan on the survival rate and ROS level of C. elegans under oxidative stress. (A) Oxidative survival curves of nematodes with or without nostoglycan treatment. Young adult nematodes were first treated with nostoglycan or EGCG at the indicated concentrations and then exposed to $70 \mathrm{mM}$ paraquat. Live nematodes were scored every $12 \mathrm{~h}$ until all dead. Representative Kaplan-Meier curves are presented from three independent experiments; (B) Representative micrographs of DCF fluorescence in paraquat-exposed nematodes. The nematodes were treated with or without $0.5 \mathrm{mg} / \mathrm{mL}$ nostoglycan prior to $10 \mathrm{mM}$ paraquat exposure and then stained with the fluorescent probe DCFH-DA. The fluorescent images were captured by an ImageXpress Micro System. Scale bars, $200 \mu \mathrm{m}$; (C) DCF fluorescence intensity of paraquat-exposed nematodes. The nematodes were treated as in $(\mathbf{B})$, and the DCF intensity was measured with a fluorescence microplate reader after DCFH-DA treatment. Data are presented as mean \pm SEM of three independent experiments. ${ }^{*} p<0.05$ (as compared to paraquat-exposed nematodes).

An excessive accumulation of ROS is known to be a major cause of oxidative stress [8], while prevention of ROS overproduction represents an efficient way to restore cellular redox balance and thus alleviate oxidative impairments. For example, a polysaccharide isolated from the mushroom Dictyophora indusiata is recently shown to attenuate chemosensory behavior dysfunction through reducing ROS level in transgenic C. elegans models of neurodegeneration, where expression of disease proteins induces ROS overproduction and causes neuronal damages [29]. Since paraquat can induce endogenous ROS overproduction, we investigated whether the protective effect of nostoglycan against oxidative stress induced by paraquat was through modulation of ROS level. As shown above, $70 \mathrm{mM}$ paraquat induced nematode death in a relatively short time $(<24 \mathrm{~h})$, and therefore, in order to make ROS determinations, we used a lower dose of paraquat $(10 \mathrm{mM})$ to induce oxidative stress but also to ensure the nematodes were still alive. The nematodes were first treated with $0.5 \mathrm{mg} / \mathrm{mL}$ nostoglycan for $48 \mathrm{~h}$ and then exposed to $10 \mathrm{mM}$ paraquat for $24 \mathrm{~h}$, and the ROS level was determined using $2^{\prime}, 7^{\prime}$-dichlorodihydrofluorescein diacetate (DCFH-DA) fluorescent probe. As shown in Figure 3B,C, the relative 2,7-dichlorofluorescein (DCF) fluorescence intensity of paraquat-exposed nematodes was higher than that of the control, indicating the ROS level was increased by paraquat itself. Interestingly, when the nematodes were pretreated with nostoglycan prior to paraquat exposure, the increased ROS level was significantly reduced $(p<0.05)$, suggesting that reduction of ROS level may contribute to the protective effect of nostoglycan against oxidative stress. 


\subsection{Reduction of Protein Carbonyl and Malonaldehyde Contents and Upregulation of Antioxidant Enzyme} Activities by Nostoglycan in C. elegans under Oxidative Stress

One of the impairments caused by excessive ROS is protein carbonyl formation, which leads to rapid degradation of proteins [34]. Another consequence of excessive ROS is the production of malonaldehyde (MDA), a lipid peroxidation product that interacts with DNA and proteins to form toxic adducts [35]. Therefore, we further examined the effect of nostoglycan on the contents of protein carbonyl groups and MDA, both of which can be used as oxidative stress markers. As shown in Table 1, the protein carbonyl and MDA contents were increased after the nematodes were exposed to $10 \mathrm{mM}$ paraquat. When the nematodes were pretreated with $0.5 \mathrm{mg} / \mathrm{mL}$ nostoglycan prior to paraquat exposure, however, the elevated protein carbonyl and MDA levels were reduced. These results demonstrate that nostoglycan is capable of inhibiting protein and lipid peroxidation in oxidative stressed animal models, possibly through reducing the ROS level. Interestingly, the MDA content of the nematodes treated with nostoglycan but without paraquat exposure was also significantly lower than that of the unexposed control nematodes, indicating the ability of the polysaccharide per se to inhibit lipid peroxidation. Increasing evidence has shown that lipid peroxidation is implicated in ageing process and age-related diseases, and inhibition of lipid peroxidation can be beneficial to retard ageing and suppress age-related diseases [36-38]. For example, Brassica chinensis extracts are recently shown to extend the lifespan of C. elegans, which is likely related to increased antioxidant enzyme activities and decreased MDA content [37]. Another example is strawberry-rich anthocyanin supplementation, which can ameliorate cardiovascular risk and reduce oxidative stress markers, including serum MDA, in healthy people [38]. Therefore, our results suggest that nostoglycan may have the potential to delay senescence and maintain health. In addition, a number of studies have shown that metal ion chelators can also reduce ROS level and inhibit lipid peroxidation $[39,40]$. Interestingly, the polysaccharides from several Nostoc species, including N. sphaeroides, are shown to have strong capacities to chelate metal ions $[17,41]$, suggesting that the antioxidant effect of nostoglycan may also be related with its chelating ability. We have previously shown that a polysaccharide from the medicinal herb Rubia cordifolia can activate proteasomal pathway in T-REx293 human embryonic kidney cells expressing amyloid $\beta$-peptide [42], which can induce protein and lipid peroxidation in cellular and animal models [43]. Therefore, the cellular protein degradation system, including autophagy and proteasomal pathways, might also contribute to the inhibition of protein and lipid peroxidation by nostoglycan under oxidative stress.

Table 1. Effect of nostoglycan on protein carbonyl and malondialdehyde contents and antioxidant enzyme activities in C. elegans.

\begin{tabular}{|c|c|c|c|c|c|}
\hline Treatment & $\begin{array}{l}\text { Protein } \\
\text { Carbonyl } \\
\text { Content }^{\text {a }}\end{array}$ & MDA Content $^{b}$ & SOD Activity $^{c}$ & CAT Activity ${ }^{d}$ & GPx Activity ${ }^{c}$ \\
\hline Nostoglycan & $0.82 \pm 0.12$ & $4.94 \pm 0.31^{\mathrm{e}}$ & $46.81 \pm 6.84$ & $1.32 \pm 0.02^{\mathrm{e}}$ & $16.87 \pm 1.50$ \\
\hline Paraquat & $1.71 \pm 0.14 \mathrm{e}^{\mathrm{e}}$ & $10.39 \pm 0.87^{\mathrm{e}}$ & $69.97 \pm 3.51^{\mathrm{e}}$ & $1.08 \pm 0.02 \mathrm{e}$ & $15.09 \pm 0.76$ \\
\hline Nostoglycan + Paraquat & $1.02 \pm 0.18^{f}$ & $7.28 \pm 0.46^{\mathrm{f}}$ & $97.88 \pm 6.72^{f}$ & $1.21 \pm 0.02^{\mathrm{f}}$ & $14.19 \pm 1.48$ \\
\hline
\end{tabular}

The nematodes were treated with or without $0.5 \mathrm{mg} / \mathrm{mL}$ of nostoglycan followed by exposure to $10 \mathrm{mM}$ of paraquat.

a Protein carbonyl content, $\mathrm{nmol} / \mathrm{mg}$ proteins; ${ }^{\mathrm{b}} \mathrm{MDA}$ content, $\mu \mathrm{M} / \mathrm{mg}$ proteins; ${ }^{\mathrm{c}} \mathrm{SOD}$ and GPx activities, $\mathrm{U} / \mathrm{mg}$ proteins; ${ }^{\mathrm{d}} \mathrm{CAT}$ activity, $\mathrm{U} / \mu \mathrm{g}$ proteins; ${ }^{\mathrm{e}} p<0.05$, compared with the control nematodes; ${ }^{\mathrm{f}} p<0.05$, compared with paraquat-intoxicated nematodes.

Antioxidant enzymes are important members of cellular antioxidant defense system and play a key role in scavenging excessive ROS and reducing oxidative damages, and many polysaccharides have been shown to regulate the activity of antioxidant enzymes. For example, we have previously shown that the polysaccharide from Angelica sinensis can increase superoxide dismutase (SOD) and glutathione peroxidase (GPx) activities in cortical tissue of rats to ameliorate cerebral ischemia injury, a complex pathological process involving oxidative stress [44]. Therefore, we tested whether the antioxidant 
effect of nostoglycan, including its capacities to improve oxidative survival and reduce ROS level as shown above, was related to its regulation of antioxidant enzyme activities. As shown in Table 1, the SOD activity was increased in the nematodes exposed to $10 \mathrm{mM}$ paraquat alone as compared to the unexposed control, suggesting an adaptive response of the nematodes to oxidative stimulation. This is consistent with previous reports showing that paraquat can stimulate SOD expression and activity in C. elegans models $[29,45]$. However, catalase (CAT) activity of the paraquat-exposed nematodes was reduced as compared to that of the control. Since SOD can convert superoxide anion to hydrogen peroxide and CAT can detoxify hydrogen peroxide to water, these results indicate that paraquat may disrupt the antioxidant defense system and cause accumulation of toxic hydrogen peroxide as demonstrated previously [33]. Interestingly, although the SOD activity of the nematodes treated with $0.5 \mathrm{mg} / \mathrm{mL}$ nostoglycan alone was almost unchanged as compared to the control, the SOD activity was further elevated when the nematodes were pretreated with nostoglycan and then exposed to paraquat as compared to that of the paraquat-exposed nematodes. Similarly, we have previously found that D. indusiata polysaccharide can increase SOD activity in paraquat-exposed C. elegans [29]. As SOD expression and activity can be regulated by many upstream regulators such as the transcription factors DAF-16/FOXO and SKN-1/Nrf2 [45,46], these findings suggest that polysaccharides and paraquat may act differently on SOD expression and activity. For example, paraquat is shown to increase SOD expression through promoting SKN-1 translocation [45] while $D$. indusiata polysaccharide is found to activate DAF-16 but not SKN-1 in C. elegans [29]. In addition to SOD, the activity of CAT was also increased in nostoglycan-treated nematodes as compared to the controls with or without paraquat exposure, respectively. The GPx activity was, however, only slightly affected by treatments with nostoglycan, paraquat or both. Taken together, these results suggest that nostoglycan is capable of scavenging toxic superoxide anions and hydroxyl radicals through regulating SOD and CAT activities under oxidative stress and that the upregulation of antioxidant enzymes is likely to play a part in the in vivo antioxidant capacity of the polysaccharide.

\subsection{Inhibition of Proliferation of Human Tumor Cells by Nostoglycan}

Oxidative stress is closely associated with tumorigenesis and cancer development, e.g. excessive ROS can induce chromosome instability and genetic mutation and also alter gene expression patterns, leading to uncontrolled cell proliferation [12]. On the other hand, antioxidant strategies are considered to be a sensible approach for intervention against cancer progression [47]. Food-derived antioxidants, for example, are known to have potentials to reduce cancer risk and slow cancer development [12,48]. Since nostoglycan has shown antioxidant capacities in several aspects as demonstrated above, we investigated whether the polysaccharide can also inhibit the proliferation of tumor cells using a number of cell lines derived from different human tissues, including lung adenocarcinoma cell line A549, hepatocellular carcinoma cell line HepG2, prostate carcinoma cell line PC3, promyelocytic leukemia cell line HL-60, breast carcinoma cell line MCF-7, and leukemic T cell line Jurkat. The cells were treated with $0.1-1.0 \mathrm{mg} / \mathrm{mL}$ nostoglycan for $48 \mathrm{~h}$ and then the proliferation rate was determined using 3-(4,5-dimethylthiazol-2-yl)-2,5-diphenyl tetrazolium bromide (MTT) method. As shown in Figure 4, when the concentration of nostoglycan was $1.0 \mathrm{mg} / \mathrm{mL}$, the inhibition against A549, HepG2, PC3, MCF-7, and Jurkat cells was $42 \%, 24 \%, 20 \%, 27 \%$ and $36 \%$, respectively, at a comparable inhibition level with $100 \mu \mathrm{g} / \mathrm{mL}$ of 5-fluoro-2'-deoxyuridine (5-FUDR), an anti-metabolite drug that is widely used for cancer therapy [49]. Interestingly, we have previously shown that the extracellular polysaccharide isolated from the spent medium of $N$. sphaeroides suspension cultures is also capable of inhibiting the proliferation of several human tumor cell lines, including BGC-823 gastric carcinoma cells and MOLT-4 acute lymphoblastic leukemia cells [50]. Together, these data demonstrate the anti-tumor potential of the antioxidant polysaccharides isolated from $N$. sphaeroides. 
A

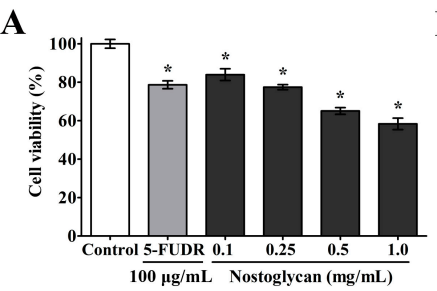

D

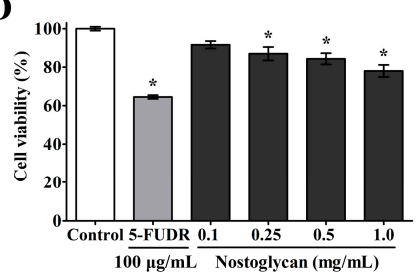

B

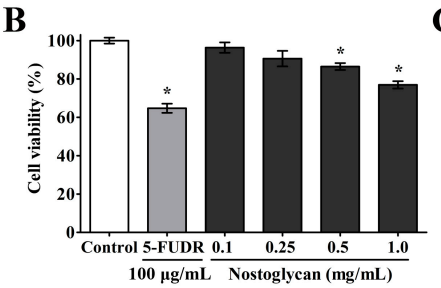

E

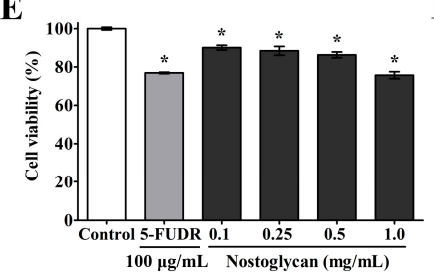

C

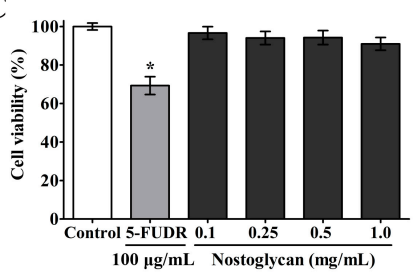

$\mathbf{F}$

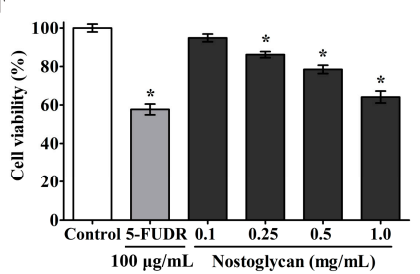

Figure 4. Effect of nostoglycan on the proliferation of tumor cells. Human tumor cell lines A549 (A); HepG2 (B); HL-60 (C); PC3 (D); MCF-7 (E); and Jurkat (F) were used to evaluate the anti-proliferative activity of nostoglycan. The tumor cells were treated with $0.1-1.0 \mathrm{mg} / \mathrm{mL}$ nostoglycan or $100 \mu \mathrm{g} / \mathrm{mL}$ 5-FUDR for $48 \mathrm{~h}$, and the cell viabilities were measured by MTT method. All data are normalized to the untreated cells and presented as mean \pm SEM of three independent experiments. ${ }^{*} p<0.05$.

\subsection{Induction of Apoptosis through Activation of Capspase-3 in Tumor Cells by Nostoglycan}

Apoptosis is a fundamental physiological process of cell death, while loss of apoptotic response contributes significantly to cancer development and multidrug resistance [51]. Targeting cell apoptosis thus offers opportunities to suppress tumor proliferation and improve cancer treatment. Since nostoglycan was capable of inhibiting proliferation of tumor cells, we further tested whether this effect was through modulation of cell apoptosis using the human lung adenocarcinoma cell line A549. The cells were treated with $1.0 \mathrm{mg} / \mathrm{mL}$ nostoglycan or $100 \mu \mathrm{g} / \mathrm{mL} 5$-FUDR for $48 \mathrm{~h}$ and then the apoptosis rates were determined by flow cytometry after Annexin V-FITC/propidium iodide (PI) staining. As shown in Figure 5, the apoptosis rates of A549 cells treated with nostoglycan and 5-FUDR were increased to $\sim 47 \%$ and $\sim 40 \%$, respectively, while that of untreated cells was $\sim 5 \%$, demonstrating the induction of apoptosis by nostoglycan in A549 cells.

It is well-established that apoptosis occurs mainly through mitochondria- and death receptor-mediated signaling pathways, both of which involve the activation of executor caspases such as caspase-3 [52]. Therefore, to explore the signaling mechanisms of nostoglycan leading to death of tumor cells, we further investigated the effect of nostoglycan on the activation of caspase-3, which plays a central role in the execution phase of cell apoptosis [52]. The A549 cells were treated with $1 \mathrm{mg} / \mathrm{mL}$ nostoglycan or $100 \mu \mathrm{g} / \mathrm{mL} 5$-FUDR for $48 \mathrm{~h}$ and then the caspase activity was determined by a colorimetric method. As shown in Figure 5E, the caspase- 3 activities were increased in cells treated with either nostoglycan or 5-FUDR, suggesting an involvement of caspase-3 activation in nostoglycan-induced cell apoptosis. In addition to induction of apoptosis, other mechanisms may also be involved in the anti-proliferative effect of Nostoc polysaccharides. For example, a polysaccharide from N. commune is able to suppress proliferation of MCF-7 cells via modulation of endoplasmic reticulum stress, which is known to trigger unfolded protein response and lead to cell death [53]. Also, a number of studies have shown that the anti-tumor activity of polysaccharides is closely associated with their regulatory effects on immune system [54,55], and, intriguingly, $N$. commune polysaccharide has been previously shown to activate the complement system [2], an important part of the immune system acting to enhance the adaptive immune response. Therefore, other mechanisms are also likely to contribute to the inhibitory effect of nostoglycan and other Nostoc polysaccharides on the proliferation of tumor cells. 
A

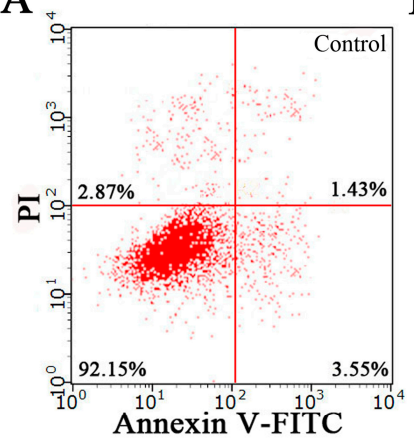

D

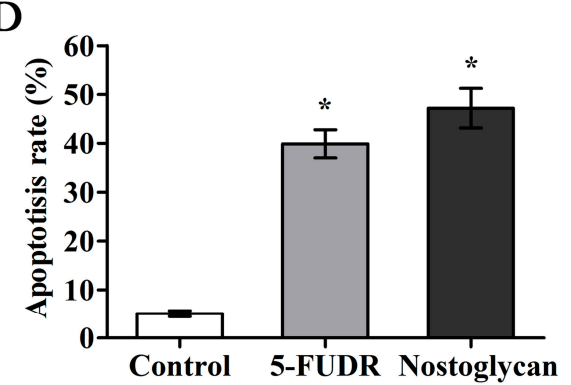

B

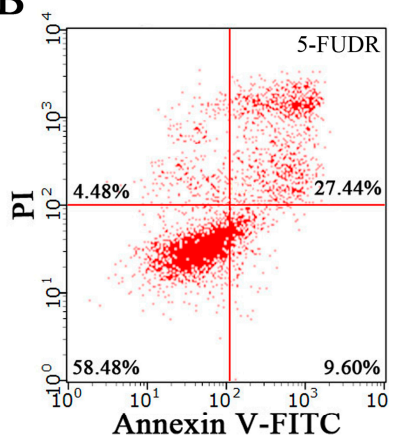

C

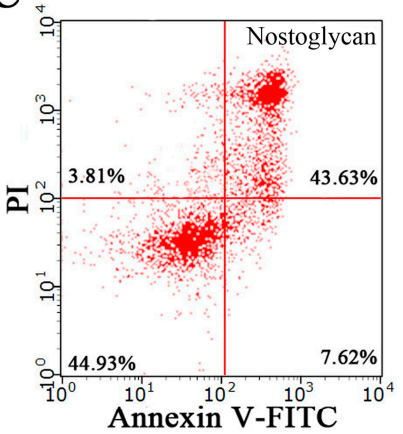

$\mathrm{E}$

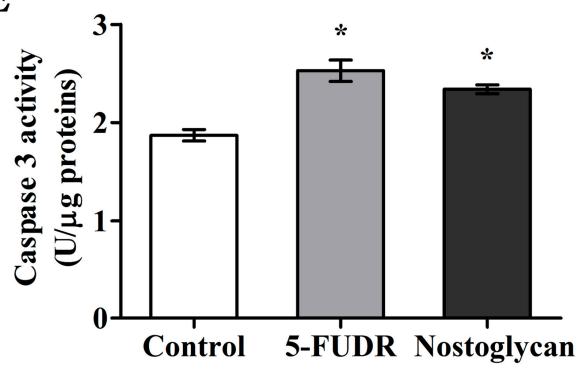

Figure 5. Effect of nostoglycan on apoptosis and caspase-3 activation in tumor cells. Quantitative analysis of apoptosis was performed by flow cytometry using human lung adenocarcinoma cell line A549. The cells were treated with medium (control; A), $100 \mu \mathrm{g} / \mathrm{mL} 5-\mathrm{FUDR}$ (B) or $1.0 \mathrm{mg} / \mathrm{mL}$ nostoglycan (C) for $48 \mathrm{~h}$ and then subjected to Annexin V-FITC/PI staining and flow cytometry analysis. Apoptosis rate was calculated as the percentage of Annexin V-positive cells in >10,000 total cells (D). The activity of caspase-3 in A549 cells was determined by colorimetric assay (E). Data are presented as mean \pm SEM of three independent experiments. ${ }^{*} p<0.05$.

\section{Materials and Methods}

\subsection{Preparation of Polysaccharide}

Colonies of Nostoc sphaeroides Kützing were grown essentially as described [56]. The stock culture was ground and grown in BG11 medium sparged with filtered air in $1 \mathrm{~L}$ conical flasks at $20^{\circ} \mathrm{C}$ and $80 \mu \mathrm{E} /\left(\mathrm{m}^{2} \mathrm{~s}\right)(16 \mathrm{~h}$ light and $8 \mathrm{~h}$ dark cycle), and the spent medium was regularly exchanged for fresh medium until the diameter of the colonies reached about $0.5 \mathrm{~mm}$. The colonies were then transferred into $5 \mathrm{~L}$ glass bottles for a larger scale culture in a similar fashion. Colonies with a diameter of 1-2 mm were collected for outdoor culture in 500 L glass tanks bubbled with filtered air at room temperature with controlled solar irradiance, and the colonies with a diameter of $\geq 5 \mathrm{~mm}$ were harvested and air-dried as N. sphaeroides products. Polysaccharide preparation was performed essentially as described previously [4]. In brief, dry N. sphaeroides colonies were ground and refluxed in ethanol. After removal of the solvent, the materials were immersed overnight in water and then subjected to hot water extraction. The supernatant was treated with $0.1 \%$ papain $(\mathrm{pH} 6.0)$ at $40{ }^{\circ} \mathrm{C}$ for $2 \mathrm{~h}$ and then precipitated with ethanol. The precipitate was redissolved in water, dialyzed, and freeze-dried as N. sphaeroides polysaccharide (nostoglycan).

\subsection{Determination of Carbohydrate Content and Analysis of Monosaccharide Composition}

Total carbohydrate content was determined by the phenol-sulfuric acid method [57]. Analysis of monosaccharides was performed by gas chromatography as described previously [29]. Briefly, the polysaccharide was first methanolyzed with methanolic $\mathrm{HCl}$ using inositol as an internal standard. The resultant methyl glycosides were then subjected to trimethylsilylation and identification on a 
CP-3800 gas chromatograph (Varian, Palo Alto, CA, USA) with a DB column $(30 \times 0.25 \mathrm{~mm}$; Agilent, Palo Alto, CA, USA).

\subsection{FTIR Spectroscopy Analysis}

FTIR spectrum of polysaccharide was determined as described previously [58]. Briefly, $1 \mathrm{mg}$ of nostoglycan powder was mixed with $110 \mathrm{mg}$ of $\mathrm{KBr}$ powder, and the mixture was pressed into a tablet. The FTIR spectrum was recorded on a Spectrum100 FTIR spectrophotometer (PerkinElmer, Waltham, MA, USA) using 32 scans at a resolution of $4 \mathrm{~cm}^{-1}$ in the frequency range of $4000-400 \mathrm{~cm}^{-1}$.

\subsection{Congo Red Binding Assay}

The triple helical conformation of polysaccharide was investigated using the azo dye Congo red as described [20]. Briefly, $2 \mathrm{~mL}$ of $1 \mathrm{mg} / \mathrm{mL}$ nostoglycan solution was mixed with $2 \mathrm{~mL}$ of $100 \mu \mathrm{M}$ Congo red solution, and then $1 \mathrm{~mL}$ of $\mathrm{NaOH}$ solution with different concentrations was added to achieve a final $\mathrm{NaOH}$ concentration of 0-0.5 M. Laminarin and dextran (Sigma, St. Louis, MO, USA) were used as controls for triple helical and random coil conformations, respectively. The $\lambda_{\max }$ of the mixture was recorded by wavelength scanning from 400 to $600 \mathrm{~nm}$ using a GENESYS 10S UV-Vis spectrophotometer (Thermo Fisher Scientific, Waltham, MA, USA).

\subsection{Surface Morphology Analysis}

The surface morphology of nostoglycan was analyzed using SEM as described previously [59]. Briefly, the dried nostoglycan powder was mounted on a copper stub using a double-sided adhesive carbon tape, and sputtered with a layer of gold using a sputter coater. The sample was then observed by a Hitachi S-3700N SEM (Hitachi, Tokyo, Japan) at an acceleration voltage of $15 \mathrm{kV}$.

\subsection{Assessment of Moisture Absorption and Retention}

The moisture absorption and retention capacities of polysaccharides were evaluated using moisture weight gain-and-loss assay as described previously [4]. To determine the Ra, the dried nostoglycan and chitosan (as a control) were placed in a sealed humidity chamber with $43 \%$ or $81 \% \mathrm{RH}$ for moisture absorption and their Ra was calculated according to the weight gained after an indicated time. To determine the $R r$, the dried polysaccharides were first fully humidified in a sealed chamber containing water and then transferred to the $43 \% \mathrm{RH}$ chamber to dehumidify for the indicated times. After that, the polysaccharides were transferred to a desiccation chamber containing dried silica gel to further dehydrate for the indicated times. The $R r$ of polysaccharides was calculated according to the weight loss of the moisturized polysaccharides after dehydration for an indicated time.

\subsection{Determination of Viscosity}

The relative viscosity of nostoglycan was determined using an Ubbelohde capillary viscometer (ShenLi Glass Labware, Shanghai, China) as previously described [60]. Briefly, $20 \mathrm{mg}$ of nostoglycan was dissolved in $20 \mathrm{~mL}$ of water and passed through a $0.45 \mu \mathrm{m}$ Millipore membrane filter. Then $10 \mathrm{~mL}$ of the nostoglycan solution or water was transferred into the viscometer, and the efflux time of nostoglycan solution and water was measured respectively. The relative viscosity was calculated as the ratio of the efflux time of the polysaccharide solution to that of water. Apple pectin and agar (Sigma) were used for comparison.

\subsection{Nematode Maintenance}

Both Caenorhabditis elegans strain N2 (wild type) and Escherichia coli strain OP50 were obtained from the Caenorhabditis Genetics Center (University of Minnesota, Minneapolis, MN, USA). C. elegans was maintained at $20^{\circ} \mathrm{C}$ on nematode growth media agar plates with E. coli OP50 as food. Synchronization of nematodes was performed using the standard alkaline hypochlorite method. 


\subsection{Paraquat Survival Assay in C. elegans}

The paraquat survival assay was performed using C. elegans in liquid culture as described previously [30]. In brief, synchronized L1 larvae were grown in S medium until L4 and then 5-FUDR (Sigma) was added to suppress reproduction. After further incubation for $24 \mathrm{~h}$, the young adult nematodes were treated with $0.1-0.5 \mathrm{mg} / \mathrm{mL}$ of nostoglycan for $48 \mathrm{~h}$ and then exposed to $70 \mathrm{mM}$ paraquat. The numbers of live and dead nematodes were scored every $12 \mathrm{~h}$ based on their movement until all dead. EGCG (final concentration of $100 \mu \mathrm{M}$ ) was used as a positive control.

\subsection{Determination of ROS Level in C. elegans}

The ROS level in C. elegans was determined using the fluorescent probe DCFH-DA as previously described [30]. Briefly, synchronized L1 nematodes were pretreated with $0.5 \mathrm{mg} / \mathrm{mL}$ of nostoglycan for $48 \mathrm{~h}$ and then exposed to $10 \mathrm{mM}$ paraquat for $24 \mathrm{~h}$. After wash with $\mathrm{M} 9$ buffer, the nematodes were dispensed into black 96-well plates (90 nematodes/well; 900 nematodes for each treatment) by a COPAS Biosort instrument (Union Biometrica, Inc., Holliston, MA, USA). DCFH-DA was then added at a final concentration of $50 \mu \mathrm{M}$ and the plates were incubated at $20^{\circ} \mathrm{C}$ for $14 \mathrm{~h}$. The images of fluorescence from the resulting DCF were captured by ImageXpress Micro System (Molecular Devices, Sunnyvale, CA, USA). The fluorescence intensity was determined using a Fluoroskan Ascent FL microplate reader (Thermo) at an excitation of $485 \mathrm{~nm}$ and an emission of $535 \mathrm{~nm}$.

\subsection{Determination of Protein Carbonyl and MDA Contents and Antioxidant Enzyme Activities in C. elegans}

Protein carbonyl content [61], MDA content [62], and antioxidant enzyme activities [62] were determined as described previously. Briefly, synchronized L1 nematodes were pretreated with $0.5 \mathrm{mg} / \mathrm{mL}$ of nostoglycan and then exposed to $10 \mathrm{mM}$ paraquat as above. Approximately 3000 nematodes were homogenized in $400 \mu \mathrm{L}$ of Western and IP lysis buffer (Beyotime, Shanghai, China). The lysate was collected by centrifugation and used for the following determinations using commercial assay kits, respectively: protein carbonyl content (Jiancheng, Nanjing, China); MDA content and SOD, CAT and GPx activities (Beyotime); and protein content (Thermo), which was used to normalize protein carbonyl and MDA contents and antioxidant enzyme activities.

\subsection{Tumor Cell Lines}

The human tumor cell lines—including A549, HepG2, PC3, HL-60, MCF-7, and Jurkat-were obtained from the Cell Resource Center of Shanghai Institutes for Biological Sciences, the Chinese Academy of Sciences (Shanghai, China). The cells were maintained in RPMI-1640 medium (A549, HepG2, HL-60, and Jurkat), DMEM/F-12 medium (PC3), or DMEM medium with high glucose (MCF-7). The culture medium was supplemented with $10 \%$ fetal bovine serum, $100 \mathrm{U} / \mathrm{mL}$ penicillin, and $100 \mu \mathrm{g} / \mathrm{mL}$ streptomycin. The cells were grown at $37{ }^{\circ} \mathrm{C}$ in a humidified atmosphere with $5 \% \mathrm{CO}_{2}$. For subculture of the adherent cell lines A549, HepG2, PC3, and MCF-7, the cells were passaged by trypsinization when the confluence reached about $80 \%$. For maintenance of the suspension cell lines HL-60 and Jurkat, the cells were diluted with fresh medium to a density of $1 \times 10^{5}$ cells $/ \mathrm{mL}$ when the cell density reached $1 \times 10^{6}$ cells $/ \mathrm{mL}$.

\subsection{Cell Viability Assay}

Cell viability was assessed using MTT as described previously [50]. Briefly, $100 \mu \mathrm{L}$ of cells were seeded at a density of $1 \times 10^{4}$ cells $/ \mathrm{mL}$ in clear 96 -well flat-bottom polystyrene microplates (NEST, Wuxi, China), which were tissue-culture treated and sterilized. After growing in normal medium for $24 \mathrm{~h}$, the medium was removed and the cells were treated with a given concentration of nostoglycan $(0.1,0.25,0.5$, and $1.0 \mathrm{mg} / \mathrm{mL})$ in respective serum-free medium for another $48 \mathrm{~h}$. Then $10 \mu \mathrm{L}$ of $5 \mathrm{mg} / \mathrm{mL}$ MTT was added to each well and the plates were incubated further at $37^{\circ} \mathrm{C}$ for $4 \mathrm{~h}$. After removal of the medium, $100 \mu \mathrm{L}$ of DMSO was added to dissolve the formazan crystals. The 
absorbance was measured at $570 \mathrm{~nm}$ on a microplate reader (Thermo Fisher, Waltham, MA, USA). 5-FUDR $(100 \mu \mathrm{g} / \mathrm{mL}$, final concentration) was used as a positive control. All data were normalized to the absorbance of the control without polysaccharide or 5-FUDR treatment.

\subsection{Flow Cytometry Analysis of Cell Apoptosis}

Apoptosis of human lung adenocarcinoma A549 cells was analyzed by flow cytometry using Annexin V/PI staining as described [63]. Briefly, $2 \mathrm{~mL}$ of the cells were seeded at a density of $1 \times 10^{5}$ cells / mL in clear 6-well flat-bottom polystyrene plates (NEST, Wuxi, China) and incubated for $24 \mathrm{~h}$. After treatment with $1.0 \mathrm{mg} / \mathrm{mL}$ nostoglycan or $100 \mu \mathrm{g} / \mathrm{mL}$ 5-FUDR (as a control) for another $48 \mathrm{~h}$, the cells were incubated with Annexin V and PI according to the instructions of Apoptosis Detection Kit (KeyGen, Nanjing, China) and then analyzed using a flow cytometer (Merck Millipore, Darmstadt, $\mathrm{HE}$, Germany) with an excitation of $488 \mathrm{~nm}$ and an emission of $530 \mathrm{~nm}$. Apoptosis was expressed as percentage of Annexin V-positive cells in >10,000 total cells analyzed in the gated region.

\subsection{Measurement of Caspase-3 Activity}

The caspase-3 activity was measured using a caspase colorimetric kit (Beyotime) as described [64]. Briefly, A549 cells were treated with nostoglycan or 5-FUDR as described in the cell apoptosis analysis. The cells were collected, washed with PBS, and lysed in the cell lysis buffer provided in the kit. The supernatant was collected and mixed with the reaction buffer in 96-well plates. After addition of the caspase- 3 colorimetric substrate Ac-DEVD- $\rho N A$, the plates were incubated at $37^{\circ} \mathrm{C}$ for $4 \mathrm{~h}$ and read at $405 \mathrm{~nm}$ in the microplate reader (Thermo Fisher). Data were normalized to protein content.

\subsection{Statistical Analysis}

Statistical analysis was performed primarily by GraphPad Prism 5.0 for Windows (GraphPad Software, San Diego, CA, USA). Statistical significance was determined by one-way ANOVA followed by Tukey's post hoc test. C. elegans survival data were analyzed by Kaplan-Meier method and log-rank test using SPSS 17.0 for Windows (SPSS, Chicago, IL, USA). All experiments were performed at least three times. A probability value of $p<0.05$ was considered statistically significant.

\section{Conclusions}

In this study, we first investigated the physicochemical properties of nostoglycan, a polysaccharide isolated from cultured N. sphaeroides colonies, and found that the polysaccharide has strong moisture absorption and retention capabilities and a high relative viscosity. Then we demonstrate that nostoglycan can increase survival rate, reduce ROS levels and protein carbonyl and MDA contents, and enhance SOD and CAT activities of C. elegans under increased oxidative stress induced by paraquat. We also show that nostoglycan is able to inhibit the proliferation of several different types of tumor cells. Using the human lung adenocarcinoma cell line A549, we further reveal that nostoglycan can induce apoptosis of tumor cells via caspase-dependent pathway. These results provide an important insight into the potentials of nostoglycan in food and health industries.

Acknowledgments: This work was supported by Guangdong Province Department of Education (grants 2015KGJHZ022 and 2016KQNCX084), the Natural Science Foundation of Guangdong Province (grant 2017A030313864), the National High-Tech R \& D Program of China (863 Program; grant 2014AA022001), and the Special Funds of the Central Finance to Support the Development of Local Universities and Colleges.

Author Contributions: Zebo Huang and Haifeng Li conceived and designed the research. Haifeng Li, Linnan Su, Sheng Chen, Libin Zhao, Hongyu Wang, Fei Ding, Hong Chen, and Ruona Shi performed the experiments. Haifeng Li, Linnan Su, Zebo Huang, and Yulan Wang analyzed the data. Haifeng Li, Linnan Su, Zebo Huang, and Yulan Wang wrote and revised the manuscript. All authors have read and approved the final version.

Conflicts of Interest: The authors declare no conflict of interest. 


\section{References}

1. Huang, Z.; Liu, Y.D.; Paulsen, B.S.; Klaveness, D. Studies on polysaccharides from three edible species of Nostoc (cyanobacteria) with different colony morphologies: Comparison of monosaccharide compositions and viscosities of polysaccharides from field colonies and suspension cultures. J. Phycol. 1998, 34, 962-968. [CrossRef]

2. Brüll, L.P.; Huang, Z.; Thomas-Oates, J.E.; Paulsen, B.S.; Cohen, E.H.; Michaelsen, T.E. Studies of polysaccharides from three edible species of Nostoc (cyanobacteria) with different colony morphologies: Structural characterization and effect on the complement system of polysaccharides from N. commune. J. Phycol. 2000, 36, 871-881. [CrossRef]

3. Deng, Z.Y.; Hu, Q.; Lu, F.; Liu, G.X.; Hu, Z.Y. Colony development and physiological characterization of the edible blue-green alga, Nostoc sphaeroides (Nostocaceae, Cyanophyta). Prog. Nat. Sci. 2008, 18, 1475-1483. [CrossRef]

4. Li, H.; Xu, J.; Liu, Y.; Ai, S.; Qin, F.; Li, Z.; Zhang, H.; Huang, Z. Antioxidant and moisture-retention activities of the polysaccharide from Nostoc commune. Carbohydr. Polym. 2011, 83, 1821-1827. [CrossRef]

5. Ku, C.S.; Pham, T.X.; Park, Y.; Kim, B.; Shin, M.S.; Kang, I.; Lee, J. Edible blue-green algae reduce the production of pro-inflammatory cytokines by inhibiting NF- $\mathrm{B}$ pathway in macrophages and splenocytes. Biochim. Biophys. Acta 2013, 1830, 2981-2988. [CrossRef] [PubMed]

6. Yang, Y.; Kim, B.; Park, Y.K.; Lee, J.Y. Effects of long-term supplementation of blue-green algae on lipid metabolism in C57BL/6J mice. J. Nutr. Health Food Sci. 2014, 1, 6. [CrossRef]

7. Ku, C.S.; Kim, B.; Pham, T.X.; Yang, Y.; Wegner, C.J.; Park, Y.K.; Balunas, M.; Lee, J.Y. Blue-green algae inhibit the development of atherosclerotic lesions in apolipoprotein E knockout mice. J. Med. Food 2015, 18, 1299-1306. [CrossRef] [PubMed]

8. Cui, H.; Kong, Y.H.; Zhang, H. Oxidative stress, mitochondrial dysfunction, and aging. J. Signal Transduct. 2012, 2012, 646354. [CrossRef] [PubMed]

9. Schieber, M.; Chandel, N.S. ROS function in redox signaling and oxidative stress. Curr. Biol. 2014, 24, R453-R462. [CrossRef] [PubMed]

10. Höll, M.; Koziel, R.; Schäfer, G.; Pircher, H.; Pauck, A.; Hermann, M.; Klocker, H.; Jansen-Dürr, P.; Sampson, N. ROS signaling by NADPH oxidase 5 modulates the proliferation and survival of prostate carcinoma cells. Mol. Carcinog. 2016, 55, 27-39. [CrossRef] [PubMed]

11. Verdile, G.; Keane, K.N.; Cruzat, V.F.; Medic, S.; Sabale, M.; Rowles, J.; Wijesekara, N.; Martins, R.N.; Fraser, P.E.; Newsholme, P. Inflammation and oxidative stress: The molecular connectivity between insulin resistance, obesity, and Alzheimer's disease. Mediators Inflamm. 2015, 2015, 105828. [CrossRef] [PubMed]

12. Prasad, S.; Gupta, S.C.; Tyagi, A.K. Reactive oxygen species (ROS) and cancer: Role of antioxidative nutraceuticals. Cancer Lett. 2017, 387, 95-105. [CrossRef] [PubMed]

13. Shebis, Y.; Iluz, D.; Kinel-Tahan, Y.; Dubinsky, Z.; Yehoshua, Y. Natural antioxidants: Function and sources. Food Nutr. Sci. 2013, 4, 643-649. [CrossRef]

14. Giavasis, I. Bioactive fungal polysaccharides as potential functional ingredients in food and nutraceuticals. Curr. Opin. Biotechnol. 2014, 26, 162-173. [CrossRef] [PubMed]

15. Potts, M. Desiccation tolerance of procaryotes. Microbiol. Rev. 1994, 58, 755-805. [PubMed]

16. Wang, G.; Hu, C.; Li, D.; Zhang, D.; Li, X.; Chen, K.; Liu, Y. The response of antioxidant systems in Nostoc sphaeroides against UV-B radiation and the protective effects of exogenous antioxidants. Adv. Space Res. 2007, 39, 1034-1042. [CrossRef]

17. Tang, J.; Hu, Z.Y.; Chen, X.W. Free radical scavenging and antioxidant enzymes activation of polysaccharide extract from Nostoc sphaeroides. Am. J. Chin. Med. 2007, 35, 887-896. [CrossRef] [PubMed]

18. Newland, P.; Bingham, B.; Tarelli, E.; Thomas, A.H. High-performance gel permeation chromatography of meningococcal polysaccharides. J. Chromatogr. 1989, 483, 406-412. [CrossRef]

19. Zhang, Y.; Li, S.; Wang, X.; Zhang, L.; Cheung, P.C.K. Advances in lentinan: Isolation, structure, chain conformation and bioactivities. Food Hydrocoll. 2011, 25, 196-206. [CrossRef]

20. Semedo, M.C.; Karmali, A.; Fonseca, L. A high throughput colorimetric assay of $\beta-1,3-D-g l u c a n s$ by Congo red dye. J. Microbiol. Methods 2015, 109, 140-148. [CrossRef] [PubMed] 
21. Nie, C.; Zhu, P.; Wang, M.; Ma, S.; Wei, Z. Optimization of water-soluble polysaccharides from stem lettuce by response surface methodology and study on its characterization and bioactivities. Int. J. Biol. Macromol. 2017, 105, 912-923. [CrossRef] [PubMed]

22. Scopelliti, P.E.; Borgonovo, A.; Indrieri, M.; Giorgetti, L.; Bongiorno, G.; Carbone, R.; Podestà, A.; Milani, P. The effect of surface nanometre-scale morphology on protein adsorption. PLoS ONE 2010, 5, e11862. [CrossRef] [PubMed]

23. Jia, S.R.; Yu, H.F.; Lin, Y.X.; Dai, Y.J. Characterization of extracellular polysaccharides from Nostoc flagelliforme cells in liquid suspension culture. Biotechnol. Bioprocess Eng. 2007, 12, 271-275. [CrossRef]

24. Nep, E.I.; Conway, B.R. Physicochemical characterization of grewia polysaccharide gum: Effect of drying method. Carbohydr. Polym. 2011, 84, 446-453. [CrossRef]

25. Helm, R.F.; Huang, Z.; Edwards, D.; Leeson, H.; Peery, W.; Potts, M. Structural characterization of the released polysaccharide of desiccation-tolerant Nostoc commune DRH-1. J. Bacteriol. 2000, 182, 974-982. [CrossRef] [PubMed]

26. Shaw, E.; Hill, D.R.; Brittain, N.; Wright, D.J.; Taüber, U.; Marand, H.; Helm, R.F.; Potts, M. Unusual water flux in the extracellular polysaccharide of the cyanobacterium Nostoc commune. Appl. Environ. Microbiol. 2003, 69, 5679-5684. [CrossRef] [PubMed]

27. Or, D.; Phutane, S.; Dechesne, A. Extracellular polymeric substances affecting pore-scale hydrologic conditions for bacterial activity in unsaturated soils. Vadose Zone J. 2007, 6, 298-305. [CrossRef]

28. Mo, K.; Cheng, C.; Zhuang, Y.; Chen, M.; Zhao, N. Conformational analysis of polysaccharide from Nostoc sphaeroides Kütz. based on atomic force microscope and rheological properties. Food Sci. 2017, 38, 49-54.

29. Zhang, J.; Shi, R.; Li, H.; Xiang, Y.; Xiao, L.; Hu, M.; Ma, F.; Ma, C.W.; Huang, Z. Antioxidant and neuroprotective effects of Dictyophora indusiata polysaccharide in Caenorhabditis elegans. J. Ethnopharmacol. 2016, 192, 413-422. [CrossRef] [PubMed]

30. Wang, Q.; Huang, Y.; Qin, C.; Liang, M.; Mao, X.; Li, S.; Zou, Y.; Jia, W.; Li, H.; Ma, C.W.; et al. Bioactive peptides from Angelica sinensis protein hydrolyzate delay senescence in Caenorhabditis elegans through antioxidant activities. Oxid. Med. Cell. Longev. 2016, 2016, 8956981. [CrossRef] [PubMed]

31. Xiang, Y.; Zhang, J.; Li, H.; Wang, Q.; Xiao, L.; Weng, H.; Zhou, X.; Ma, C.W.; Ma, F.; Hu, M.; et al. Epimedium polysaccharide alleviates polyglutamine-induced neurotoxicity in Caenorhabditis elegans by reducing oxidative stress. Rejuvenation Res. 2017, 20, 32-41. [CrossRef] [PubMed]

32. Liu, K.X.; Edwards, B.; Lee, S.; Finelli, M.J.; Davies, B.; Davies, K.E.; Oliver, P.L. Neuron-specific antioxidant OXR1 extends survival of a mouse model of amyotrophic lateral sclerosis. Brain 2015, 138, 1167-1181. [CrossRef] [PubMed]

33. Suntres, Z.E. Role of antioxidants in paraquat toxicity. Toxicology 2002, 180, 65-77. [CrossRef]

34. Medina-Navarro, R.; Nieto-Aguilar, R.; Alvares-Aguilar, C. Protein conjugated with aldehydes derived from lipid peroxidation as an independent parameter of the carbonyl stress in the kidney damage. Lipids Health Dis. 2011, 10, 201. [CrossRef] [PubMed]

35. Ayala, A.; Muñoz, M.F.; Argüelles, S. Lipid peroxidation: Production, metabolism, and signaling mechanisms of malondialdehyde and 4-hydroxy-2-nonenal. Oxid. Med. Cell. Longev. 2014, 2014, 360438. [CrossRef] [PubMed]

36. Ramana, K.V.; Srivastava, S.; Singhal, S.S. Lipid peroxidation products in human health and disease 2014. Oxid. Med. Cell. Longev. 2014, 2014, 162414. [CrossRef] [PubMed]

37. Chen, J.; Zhang, J.; Xiang, Y.; Xiang, L.; Liu, Y.; He, X.; Zhou, X.; Liu, X.; Huang, Z. Extracts of Tsai Tai (Brassica chinensis): Enhanced antioxidant activity and anti-aging effects both in vitro and in Caenorhabditis elegans. Food Funct. 2016, 7, 943-952. [CrossRef] [PubMed]

38. Alvarez-Suarez, J.M.; Giampieri, F.; Tulipani, S.; Casoli, T.; Di Stefano, G.; González-Paramás, A.M.; Santos-Buelga, C.; Busco, F.; Quiles, J.L.; Cordero, M.D.; et al. One-month strawberry-rich anthocyanin supplementation ameliorates cardiovascular risk, oxidative stress markers and platelet activation in humans. J. Nutr. Biochem. 2014, 25, 289-294. [CrossRef] [PubMed]

39. Aldini, G.; Vistoli, G.; Stefek, M.; Chondrogianni, N.; Grune, T.; Sereikaite, J.; Sadowska-Bartosz, I.; Bartosz, G. Molecular strategies to prevent, inhibit, and degrade advanced glycoxidation and advanced lipoxidation end products. Free Radic. Res. 2013, 47 (Suppl. 1), 93-137. [CrossRef] [PubMed] 
40. Aguirre, P.; García-Beltrán, O.; Tapia, V.; Muñoz, Y.; Cassels, B.K.; Núñez, M.T. Neuroprotective effect of a new 7,8-dihydroxycoumarin-based $\mathrm{Fe}^{2+} / \mathrm{Cu}^{2+}$ chelator in cell and animal models of Parkinson's disease. ACS Chem. Neurosci. 2017, 8, 178-185. [CrossRef] [PubMed]

41. De Philippis, R.; Paperi, R.; Sili, C. Heavy metal sorption by released polysaccharides and whole cultures of two exopolysaccharide-producing cyanobacteria. Biodegradation 2007, 18, 181-187. [CrossRef] [PubMed]

42. Chakrabortee, S.; Liu, Y.; Zhang, L.; Matthews, H.R.; Zhang, H.; Pan, N.; Cheng, C.R.; Guan, S.H.; Guo, D.A.; Huang, Z.; et al. Macromolecular and small-molecule modulation of intracellular A $\beta 42$ aggregation and associated toxicity. Biochem. J. 2012, 442, 507-515. [CrossRef] [PubMed]

43. Cheignon, C.; Tomas, M.; Bonnefont-Rousselot, D.; Faller, P.; Hureau, C.; Collin, F. Oxidative stress and the amyloid beta peptide in Alzheimer's disease. Redox Biol. 2018, 14, 450-464. [CrossRef] [PubMed]

44. Lei, T.; Li, H.; Fang, Z.; Lin, J.; Wang, S.; Xiao, L.; Yang, F.; Liu, X.; Zhang, J.; Huang, Z.; et al. Polysaccharides from Angelica sinensis alleviate neuronal cell injury caused by oxidative stress. Neural Regen. Res. 2014, 9 , 260-267. [CrossRef] [PubMed]

45. Meng, J.; Lv, Z.; Qiao, X.; Li, X.; Li, Y.; Zhang, Y.; Chen, C. The decay of redox-stress response capacity is a substantive characteristic of aging: Revising the redox theory of aging. Redox Biol. 2017, 11, 365-374. [CrossRef] [PubMed]

46. Seo, H.W.; Cheon, S.M.; Lee, M.H.; Kim, H.J.; Jeon, H.; Cha, D.S. Catalpol modulates lifespan via DAF-16/FOXO and SKN-1/Nrf2 activation in Caenorhabditis elegans. Evid. Based Complement. Alternat. Med. 2015, 2015, 524878. [CrossRef] [PubMed]

47. Fuchs-Tarlovsky, V. Role of antioxidants in cancer therapy. Nutrition 2013, 29, 15-21. [CrossRef] [PubMed]

48. Zhou, Y.; Zheng, J.; Li, Y.; Xu, D.; Li, S.; Chen, Y.M.; Li, H.B. Natural polyphenols for prevention and treatment of cancer. Nutrients 2016, 8, 515-549. [CrossRef] [PubMed]

49. Longley, D.B.; Harkin, D.P.; Johnston, P.G. 5-Fluorouracil: Mechanisms of action and clinical strategies. Nat. Rev. Cancer 2003, 3, 330-338. [CrossRef] [PubMed]

50. Li, H.; Li, Z.; Xiong, S.; Zhang, H.; Li, N.; Zhou, S.; Liu, Y.; Huang, Z. Pilot-scale isolation of bioactive extracellular polymeric substances from cell-free media of mass microalgal cultures using tangential-flow ultrafiltration. Process Biochem. 2011, 46, 1104-1109. [CrossRef]

51. Goldar, S.; Khaniani, M.S.; Derakhshan, S.M.; Baradaran, B. Molecular mechanisms of apoptosis and roles in cancer development and treatment. Asian Pac. J. Cancer Prev. 2015, 16, 2129-2144. [CrossRef] [PubMed]

52. Xiong, S.; Mu, T.; Wang, G.; Jiang, X. Mitochondria-mediated apoptosis in mammals. Protein Cell 2014, 5, 737-749. [CrossRef] [PubMed]

53. Guo, M.; Ding, G.B.; Guo, S.; Li, Z.; Zhao, L.; Li, K.; Guo, X. Isolation and antitumor efficacy evaluation of a polysaccharide from Nostoc commune Vauch. Food Funct. 2015, 6, 3035-3044. [CrossRef] [PubMed]

54. Liu, A.J.; Yu, J.; Ji, H.Y.; Zhang, H.C.; Zhang, Y.; Liu, H.P. Extraction of a novel cold-water-soluble polysaccharide from Astragalus membranaceus and its antitumor and immunological activities. Molecules 2017, 23, E62. [CrossRef] [PubMed]

55. Fedorov, S.N.; Ermakova, S.P.; Zvyagintseva, T.N.; Stonik, V.A. Anticancer and cancer preventive properties of marine polysaccharides: Some results and prospects. Mar. Drugs 2013, 11, 4876-4901. [CrossRef] [PubMed]

56. Li, D.H.; Liu, Y.D.; Song, L.R. Hormogonia mass differentiation from Nostoc sphaeroides Kütz. (cyanobacterium) and the comparison of structural characteristics between hormogonia and vegetative filaments. Phycol. Res. 2001, 49, 81-87. [CrossRef]

57. Dubois, M.; Gilles, K.A.; Hamilton, J.K.; Rebers, P.A.; Smith, F. Colorimetric method for determination of sugars and related substances. Anal. Chem. 1956, 28, 350-356. [CrossRef]

58. Li, S.; Shah, N.P. Characterization, antioxidative and bifidogenic effects of polysaccharides from Pleurotus eryngii after heat treatments. Food Chem. 2016, 197, 240-249. [CrossRef] [PubMed]

59. Xu, Y.; Liu, G.; Yu, Z.; Song, X.; Li, X.; Yang, Y.; Wang, L.; Liu, L.; Dai, J. Purification, characterization and antiglycation activity of a novel polysaccharide from black currant. Food Chem. 2016, 199, 694-701. [CrossRef] [PubMed]

60. Cai, J.; Bo, S.; Cheng, R.; Jiang, L.; Yang, Y. Analysis of interfacial phenomena of aqueous solutions of polyethylene oxide and polyethylene glycol flowing in hydrophilic and hydrophobic capillary viscometers. J. Colloid Interface Sci. 2004, 276, 174-181. [CrossRef] [PubMed] 
61. Li, X.; Zhang, Y.; Yuan, Y.; Sun, Y.; Qin, Y.; Deng, Z.; Li, H. Protective effects of selenium, vitamin E, and purple carrot anthocyanins on D-galactose-induced oxidative damage in blood, liver, heart and kidney rats. Biol. Trace Elem. Res. 2016, 173, 433-442. [CrossRef] [PubMed]

62. Xiao, L.; Li, H.; Zhang, J.; Yang, F.; Huang, A.; Deng, J.; Liang, M.; Ma, F.; Hu, M.; Huang, Z. Salidroside protects Caenorhabditis elegans neurons from polyglutamine-mediated toxicity by reducing oxidative stress. Molecules 2014, 19, 7757-7769. [CrossRef] [PubMed]

63. Ai, S.; Jia, T.; Ai, W.; Duan, J.; Liu, Y.; Chen, J.; Liu, X.; Yang, F.; Tian, Y.; Huang, Z. Targeted delivery of doxorubicin through conjugation with EGF receptor-binding peptide overcomes drug resistance in human colon cancer cells. Br. J. Pharmacol. 2013, 168, 1719-1735. [CrossRef] [PubMed]

64. Xue, L.; Li, J.; Li, Y.; Chu, C.; Xie, G.; Qin, J.; Yang, M.; Zhuang, D.; Cui, L.; Zhang, H.; et al. N-acetylcysteine protects Chinese hamster ovary cells from oxidative injury and apoptosis induced by microcystin-LR. Int. J. Clin. Exp. Med. 2015, 8, 4911-4921. [PubMed]

Sample Availability: Samples of the compounds are available from the authors.

(C) 2018 by the authors. Licensee MDPI, Basel, Switzerland. This article is an open access article distributed under the terms and conditions of the Creative Commons Attribution (CC BY) license (http://creativecommons.org/licenses/by/4.0/). 